\title{
Childhood bronchial asthma and its associated factors: a study from a tertiary care teaching hospital of coastal Karnataka, India
}

\author{
Dogra L. ${ }^{1}$, Bhatt S. ${ }^{2}$, Shetty D. ${ }^{3}$ \\ ${ }^{1}$ Dr. Luvdeep Dogra, Department of Nephrology, Osmania Medical College, Hyderabad, ${ }^{2}$ Dr. Sonia Bhatt, Department of \\ Pediatrics, FH Medical College \& Hospital, Agra, Uttar Pradesh, ${ }^{3}$ Dr. Deepa Shetty, Department of Pediatrics, \\ Dr. B.A.M Central Railway Hospital, Mumbai.
}

Corresponding Author: Dr. Sonia Bhatt, Professor, Department of Pediatrics, FH Medical College \& Hospital, Agra, Uttar Pradesh. E-mail: soniabhatt19@gmail.com

\begin{abstract}
Background: Understanding of clinical profile and associated risk factors such as family history, exposure to smoke (indoor/outdoor), allergen, and others may help taking suitable and timely preventive measures. Therefore Aim: This study aims to find the clinical profile and associated factors with bronchial asthma among children from south India. Methods: This study was conducted at the Department of Paediatrics, Kasturba Medical College located at Manipal during 2013-2014. After taking detailed history, study subjects were taken and examined clinically on this basis for active wheeze/whistling. Relevant information on demography, environmental, and risk factors associated with asthma were noted. Results: $45.5 \%$ had symptoms suggestive of intermittent asthma, $28.7 \%$ had mild persistent asthma, and $21.9 \%$ had symptoms consistent with moderate persistent disease. $44.8 \%$ qualified as early onset asthma i.e. onset before 3 years of age. $75.9 \%$ children had h/o allergic diathesis; with allergic rhinitis being the most common manifestation (70.34\%). Seasonal variation $(81.3 \%)$ was the most commonly encountered triggering factor, followed by h/o preceding upper respiratory infection $(80 \%)$, dust exposure $(74.5 \%)$ and smoke exposure $(62.7 \%)$. Conclusion: There was high prevalence of asthma among children in this study. The mean age at presentation and clinical profile of the early onset and late onset asthma groups was similar and comparable. Seasonal exacerbation of symptoms was the most common triggering event.
\end{abstract}

Keywords: Bronchial asthma, Allergic, Children, Risk factor

\section{Introduction}

Bronchial asthma (BA) remains a public health problem in various geographical areas of the world irrespective of their level of development, being grossly underreported, under-diagnosed and under-treated and most asthma-related deaths frequently occurs in low-income and lower-middle income countries [1]. Asthma is reported to be one of the most common chronic diseases in childhood, impairing not only the quality of life of such families but also adversely affecting economic balance of the same [2].

The most used drug classes of childhood asthma medications are beta- 2 adrenergic agonists, corticosteroids, and leukotriene modifiers. Omalizumab, a monoclonal antibody against $\mathrm{IgE}$, is an

Manuscript received: $10^{\text {th }}$ July 2019

Reviewed: $20^{\text {th }}$ July 2019

Author Corrected: $27^{\text {th }}$ July 2019

Accepted for Publication: $31^{\text {st }}$ July 2019 immunomodulatory biological agent, used as new drug with confirmed IgE-mediated allergic asthma, only for patient's specific range of total IgE level. There are low evidences in the efficacy of metotrexate, as well as macrolide antibiotics in children with asthma. Nonpharmacological measures that may improve patient's quality of life should also be attempted [3].

A multifold increase in incidence of bronchial asthma has been reported in the past decade. It is a common chronic disease in pediatrics characterized by wheezing and repeated attacks of breathlessness, whereas chest tightness and dyspnea are other symptoms of asthma $[4,5]$.

It is a chronic inflammatory disease of the airway associated with broncho-constriction which leads to airflow obstruction [6]. 
Childhood Bronchial Asthma has multifactor causation. Geographical location, environmental, racial, as well as factors related to behaviours and life-styles are associated with the disease [7]. Understanding of associated risk factors such as family history, exposure to smoke (indoor/outdoor), allergen, and others may help taking suitable and timely preventive measures.

Hardly any study is available in literature in this regard from southern part of India. Therefore this study aims to find the clinical profile and associated factors with bronchial asthma among children from south India.

\section{Materials \& Methods}

This study was planned and executed by the Department of Paediatrics of a Medical College located at Manipal. Asthma was defined as paroxysms of dyspnoea, cough and wheeze of varying severity which resolves spontaneously or with therapy.

Study setting: Hospital based study

Study duration: 2013-2014

Type of study: Observational study

Sampling methods: All the subjects fulfilling inclusion and exclusion criteria were taken.

Sample size: All the subjects falling in the study period were included.

Inclusion criteria: Children between 5 to 15 years of age presenting to the Pediatric OPD, during the study period with symptoms of recurrent wheeze, cough, dyspnea - more at night / early morning of at least 3 months duration, were included in the study.

\section{Original Research Article}

Exclusion criteria: Exclusion criteria were, children receiving bronchodilators within $12 \mathrm{hrs}$ prior to assessment, children with known congenital heart disease/chest deformity, underlying lung parenchymal or structural disease and immunocompromised children were excluded from the study.

Ethical consideration \& permission: Permission of ethical committee was sought from the Institutional Ethics Committee before commencement of the study. Written informed consent was obtained.

Any scoring system: Severity of asthma was categorised as intermittent or persistent (mild, moderate or severe) based on symptoms as per NAEPP-EPR 3 guidelines. ${ }^{7}$ For the purpose of this study, subjects were subdivided based on the age at onset of symptoms. Group A consisting of children with early onset of disease (prior and up to 3 years age) and Group B with onset beyond 3 years.

Data collection procedure: After taking detailed history, study subjects were taken and examined clinically on this basis for active wheeze/whistling. Relevant information on demography, environmental, and risk factors associated with asthma were noted Asthmatic symptoms and severity (cough, wheeze and breathlessness), other associated symptoms (rhinitis, conjunctivitis and dermatitis), various precipitating factors and family history of asthma were recorded.

Data analysis: Statistical analysis was done using Statistical Package for Social Sciences (SPSS), version 21 (IBM, Chicago, USA). Study results were expressed using appropriate statistical methods like percentages and proportions.

\section{Results}

A total of sixty-six subjects (45.5\%), had symptoms suggestive of intermittent asthma, forty-two subjects (28.7\%) had mild persistent asthma, thirty-two subjects $(21.9 \%)$ had symptoms consistent with moderate persistent disease and only five had severe persistent asthma (3.4\%). None of the cases between 5-10yrs age had symptoms of severe persistent asthma. (Table 1)

Table-1: Age wise distribution of severity of asthma cases among study subjects.

\begin{tabular}{|c|c|c|c|c|}
\hline Age group & $\begin{array}{c}\text { Intermittent } \\
\text { asthma } \\
(66 / 145 ; 45.5 \%)\end{array}$ & $\begin{array}{c}\text { Mildpersistent } \\
\text { asthma } \\
(42 / 145 ; 28.7 \%)\end{array}$ & $\begin{array}{c}\text { Moderate } \\
\text { persistent asthma } \\
(32 / 145 ; 21.9 \%)\end{array}$ & $\begin{array}{c}\text { Severe } \\
\text { persistent asthma } \\
(5 / 145 ; 3.4 \%)\end{array}$ \\
\hline $\begin{array}{c}5.01-10 \text { years } \\
(\mathrm{n}=80)\end{array}$ & $40(50 \%)$ & $21(26.2 \%)$ & $19(23.8 \%)$ & - \\
\hline $\begin{array}{c}10.01-15 y e a r s \\
(\mathrm{n}=65)\end{array}$ & $26(40 \%)$ & $21(32.3 \%)$ & $13(20 \%)$ & $5(7.7 \%)$ \\
\hline \multicolumn{4}{|c}{ In parenthesis, grade wise distribution between different age groups } \\
\hline
\end{tabular}




\section{Original Research Article}

Sixty-five cases $(44.8 \%, n=65)$ qualified as early onset asthma i.e. onset before 3 years of age. Of these, 28 children had onset of symptoms in infancy (43.07\%).Eighty cases (55.5\%) had late onset disease, i.e. onset beyond 3 years of age. $75.9 \%$ children had $\mathrm{h} / \mathrm{o}$ allergic diathesis; with allergic rhinitis being the most common manifestation $(70.34 \%) .53 .1 \%$ children (77, out of 145) had a family h/o Bronchial asthma. Twenty-three subjects $(19 \%, \mathrm{n}=121)$ had low birth weight. (Table 2)

Table-2: Clinical profile of asthma among study subjects.

\begin{tabular}{|l|l|l|}
\hline Factors & Early $(\leq 3$ years $)$ & Late $(>3$ years $)$ \\
\hline Onset of wheeze: $(\mathrm{n}=145)$ & $65(44.8 \%)$ & $80(55.2 \%)$ \\
\hline Mean age at inclusion & 9.21 years & 10.33 years \\
\hline Family h/o asthma $(77 / 145,53.1 \%)$ & $37 / 65(56.9 \%)$ & $40 / 80(50 \%)$ \\
\hline H/o & & 54 \\
\hline Allergic rhinitis & 48 & 21 \\
\hline Allergic conjunctivitis & 20 & 04 \\
\hline Atopic dermatitis, $\mathrm{n}=111 / 145,75.9 \%$ & 02 & $16 / 65(24.61 \%)$ \\
\hline Birth weight $<2.5 \mathrm{Kg}(23 / 121,19 \%)$ & $7 / 56(12.5 \%)$ & 67 \\
\hline Duration of breast feeding $(\mathrm{n}=127)$ & 60 & $4 / 67(5.9 \%)$ \\
\hline Upto 6months & $6 / 60(10 \%)$ & $17 / 67(25.4 \%)$ \\
\hline $6-12$ months & $7 / 60(11.6 \%)$ & $46 / 67(68.65 \%)$ \\
\hline$>12$ months & $47 / 60(78.4 \%)$ & \\
\hline Addition of cow's milk $(\mathrm{n}=126)$ & & $20 / 65(30.77 \%)$ \\
\hline First 6months & $15 / 61(24.59 \%)$ & $32 / 65(49.23 \%)$ \\
\hline 6-12months & $24 / 61(39.34 \%)$ & $13 / 65(20 \%)$ \\
\hline$>12$ months & $22 / 61(36.06 \%)$ & \\
\hline
\end{tabular}

Frequency of various triggering factors was studied in early and late onset groups. Seasonal variation (81.3\%) was the most commonly encountered triggering factor, followed by h/o preceding upper respiratory infection (80\%), dust exposure (74.5\%) and smoke exposure $(62.7 \%)$ (Table 3$)$.

Table 3: Triggering factors among early and late onset groups of study subjects.

\begin{tabular}{|c|c|c|c|}
\hline Triggering factor & Early onset & Late onset & Total \\
\hline Seasonal variation $(\mathrm{n}=145)$ & $54 / 65(83.1 \%)$ & $64 / 80(80 \%)$ & $118 / 145(81.3 \%)$ \\
\hline Dust exposure $(\mathrm{n}=145)$ & $51 / 65(78.5 \%)$ & $57 / 80(71.2 \%)$ & $108 / 145(74.5 \%)$ \\
\hline Upper respiratory infection $(\mathrm{n}=145)$ & $55 / 65(84.6 \%)$ & $61 / 80(76.2 \%)$ & $116 / 145(80.0 \%)$ \\
\hline Play induced $(\mathrm{n}=145)$ & $40 / 65(61.5 \%)$ & $46 / 80(57.5 \%)$ & $86 / 145(59.3 \%)$ \\
\hline Smoke exposure $(\mathrm{n}=141)$ & $42 / 64(65.6 \%)$ & $49 / 77(63.6 \%)$ & $91 / 145(62.7 \%)$ \\
\hline Food allergy $(\mathrm{n}=145)$ & $29 / 65(44.6 \%)$ & $29 / 80(36.2 \%)$ & $58 / 145(40.0 \%)$ \\
\hline H/o pet exposure $(\mathrm{n}=145)$ & $23 / 65(35.4 \%)$ & $21 / 80(26.2 \%)$ & $44 / 145(30.3 \%)$ \\
\hline
\end{tabular}

\section{Discussion}

A multifold rise in incidence of bronchial asthma has been witnessed in the recent past [8]. This rise possibly be attributed mainly by increasing environmental smoke and air pollution due to rapid industrialization of cities [9]. Most children develop asthma in early age. Many previous studies on asthma in India reported an estimated prevalence rate of $2 \%$ up to as high as $23 \%$ [10,11]. A study conducted in Bangalore city among less than 18 years of age showed that asthma prevalence increased to quite a great extent from the year 1979 (9\%) to 1999 (29.5\%) [12]. In the study Vishwanathan $\mathrm{R}$ et al. reported a prevalence of $0.2 \%$ in children below 


\section{Original Research Article}

nine years [13]. Such huge variation is not only due to difference in methodology of studies but also wide geographical and environmental variations in India. Contribution of various risk factors associated with incidence of asthma may vary with geographical locations, local traditions customs, and environmental factors.

Childhood asthma causes aren't fully understood. Some factors thought to be involved include inherited tendency to develop allergies, parents with asthma, and some types of airway infections at a very young age, exposure to environmental factors, such as cigarette smoke or other air pollution. Increased immune system sensitivity causes the lungs and airways to swell and produce mucus when exposed to certain triggers.

Reaction to a trigger can be delayed, making it more difficult to identify the trigger. Triggers vary from child to child and can include viral infections such as the common cold, exposure to air pollutants, such as tobacco smoke, allergies to dust mites, pet dander, pollen or mold, weather changes or cold air, and sometimes, asthma symptoms occur with no apparent triggers.

ISSAC study compared the prevalence rates of asthma in 56 countries in children aged between 6-7 and 13-14 years. Prevalence was $17-30 \%$ in the United Kingdom, New Zealand, and Australia whereas areas of low prevalence (1-7\%) included Eastern Europe, China, and Indonesia [14]. There is a wide variation of asthma even in India, with prevalence ranging from $3.3 \%$ in Lucknow to $11.6 \%$ in New Delhi [15].

Asthma is often under-diagnosed [14] Physician label of asthma was given only in $15 \%$ of asthmatics partly because of visits to local pharmacists and medical shopkeepers. Only $5.3 \%$ had physician-diagnosed asthma ever in urban schools in Jaipur [17].

Asthma is being increasingly diagnosed nowadays indicating increasing prevalence, but reasons for the same are still poorly understood. A study by Taylor et al. depicts burden of childhood asthma on US society in terms of 2.7 million children affected annually comprising 7.3 million days of restriction to bed, 10.1 million days of absence from school, 12.9 million contacts with doctors, and 2 lakh hospitalization resulting in 1.9 million days of hospital admissions [18].There are many studies on prevalence of childhood asthma in India with majority showing increasing trends but the steering committee of ISAAC, in 1998, found
$6.0 \%$ Current Wheeze and $4.5 \%$ ever asthma in India, however, there were wide variations in the prevalence from different regions however there are concerns that prevalence may have been underestimated due to various reasons [19].

It was observed that $45.5 \%$, had symptoms suggestive of intermittent asthma, forty-two subjects (28.7\%) had mild persistent asthma, thirty-two subjects (21.9\%) had symptoms consistent with moderate persistent disease and only five had severe persistent asthma (3.4\%).

None of the cases between 5-10yrs age had symptoms of severe persistent asthma. Qureshi UA et al from Jammu and Kashmir observed that majority of asthmatic children $78.3 \%$ had probable asthma; $6.7 \%$ had definite asthma; and $15 \%$ had physician-diagnosed asthma [20]. Majority of children had intermittent asthma 78.3\%. Mild persistent asthma was seen in $12.7 \%$ and $10 \%$ had moderate persistent asthma. None of the children had severe persistent asthma.

In this study $55.5 \%$ had late onset disease, i.e. onset beyond 3 years of age. This is similar to the findings of another study from Taiwan as per that study, $42.3 \%$ with early onset and $57.7 \%$ had late onset disease [21].

It was observed that $75.9 \%$ children had $\mathrm{h} / \mathrm{o}$ allergic diathesis; with allergic rhinitis being the most common manifestation $(70.34 \%) .53 .1 \%$ children (77, out of 145 ) had a family h/o Bronchial asthma. Many studies have shown strong correlation between positive family $\mathrm{h} / \mathrm{o}$ atopy and bronchial asthma [22].

In the present study it was observed that twenty-three subjects $(19 \%, \mathrm{n}=121)$ had low birth weight. Recently a meta-analysis had observed that the children with low birth weight have an approximately $16 \%$ higher risk of asthma compared with those with normal birth weight.

Preterm infants have an increased risk of asthma compared with term neonates [23]. Moreover, children with a high birth weight or body weight later are at increased risk for future asthma [24]. The underlying biological mechanisms of this increased risk might include diet, gastro-oesophageal reflux, mechanical effects of obesity, atopy, and hormonal influences [25].

There are some limitations of this investigation as well. Smaller sample size is definitely an evident limitation of this study. It was a hospital-based study, that's another limitation. Recall bias may also be a limitation. Findings of this study may not be generalized. 


\section{Conclusion}

This study observed the high prevalence of asthma among children. The mean age at presentation and clinical profile of the early onset and late onset asthma groups was similar and comparable.

Seasonal exacerbation of symptoms was the most common triggering event. Due to lack of national data on the burden and risk factors of the disease, there is a felt need for public health research in this field on priority basis.

\section{What does the present study adds to existing knowledge?}

Prevalence of asthma among children is more in the study area (coastal region of southern Karnataka). Findings of this study add to the national data on burden and risk factors of childhood asthma.

\section{Author's Contribution}

- Dr. Luvdeep Dogra: Concept, design, manuscript preparation, data acquisition, review and guarantor.

- Dr. Sonia Bhatt: Manuscript editing, reviewing the manuscript.

- Dr. Deepa Shetty: Literature search, data analysis, manuscript editing and review.

Funding: Nil, Conflict of interest: None initiated,

Permission from IRB: Yes

\section{References}

1. Tesse R, Borrelli G, Mongelli G, Mastrorilli V, Cardinale F. Treating pediatric asthma according guidelines. Front Pediatr. 2018; 6:234. doi: 10.3389/ fped. 2018.00234

2. Bush A, Fleming L. Diagnosis and management of asthma in children. BMJ. 2015;350:h996. doi: 10.1136/ bmj.h996.

3. Reddy MB, Covar RA. Asthma phenotypes in childhood. Curr Opin Allergy Clin Immunol. 2016; 16(2): 127-34. doi: 10.1097/ACI.0000000000000252

4. Zedan M, Settin A, Farag M, Ezz-Elregal M, Osman E, Fouda A. Prevalence of bronchial asthma among Egyptian school children. Egypt J Bronchol. 2009; 3(2): 124-30.
5. Ho SM. Environmental epigenetics of asthma: an update. J Allergy Clin Immunol. 2010;126(3):453-65. doi: 10.1016/j.jaci.2010.07.030.

6. Hamam F, Eldalo A, Albarraq A, Khaleel M, Kaabi $\mathrm{Y}, \mathrm{Al}$ Ghamdi $\mathrm{A}$, et al. The prevalence of asthma and its related risk factors among the children in Taif area, Kingdom of Saudi Arabia. Saudi J Health Sci. 2015; 4(3): 179-84. doi: 10.4103/2278-0521.171436

7. Urbano FL. Review of the NAEPP 2007 Expert Panel Report (EPR-3) on asthma diagnosis and treatment guidelines. J Manag Care Pharm. 2008; 14(1):41-9. doi: 10. $18553 /$ jmcp.2008.14.1.41

8. Lai CK, Beasley R, Crane J, Foliaki S, Shah J, Weiland S. International Study of Asthma and Allergies in Childhood Phase Three Study Group. Global variation in the prevalence and severity of asthma symptoms: Phase Three of the International Study of Asthma and Allergies in Childhood (ISAAC). Thorax. 2009; 64(6): 476-83. doi: 10.1136/thx.2008.106609. Epub 2009 Feb 22.

9. Arora K, Das RR, Pooni PA, Rustagi R, Singh D. A study of the prevalence and risk factors of asthma in urban schools of Ludhiana, Punjab. Indian J Health Sci. 2015; 8(2):104-8. doi: 10.4103/2349-5006.174237

10. Kumar GS, Roy G, Subitha L, Sahu SK. Prevalence of bronchial asthma and its associated factors among school children in urban Puducherry, India. J Nat Sci Biol Med. 2014;5(1):59-62. doi: 10.4103/0976-9668. 127289

11. Sharma BS, Gupta MK, Chandel R. Prevalence of asthma in urban school children in Jaipur, Rajasthan. Ind Pediatrics. 2012;49(10):835-6.

12. Paramesh H. Epidemiology of Bronchial Asthma in India. Indian J Pediatr. 2002;69(4):309-12.

13. Vishwanathan R, Prasad M, Thakur AK, Sinha SP, Prakash N, Mody RK, et al. Epidemiology of asthma in an urban population: A random morbidity survey. J Indian Med Assoc. 1966;46(9):480-3.

14. Pal R, Dahal S, Pal S. Prevalence of bronchial asthma in Indian children. Indian J Community Med 2009; 34(4):310-6.doi: 10.4103/0970-0218.58389. 


\section{Original Research Article}

15. Awasthi S, Kalra E, Roy S, Awasthi S. Prevalence and risk factors of asthma and wheeze in school-going children in Lucknow, North India. Indian Pediatr. 2004; 41(12):1205-10.

16. Kaur J, Chugh K, Sachdeva A, Satyanarayana L. Under diagnosis of asthma in school children and its related factors. Indian Pediatr. 2007;44(6):425-8.

17. Narayanappa D, Rajani HS, Mahendrappa KB, Ravikumar VG. Prevalence of asthma in urban school children in Jaipur, Rajasthan. Indian Pediatr. 2012;49: 835-6.

18. Taylor WR, Newacheck PW. Impact of childhood asthma on health. Pediatr. 1992;90(5):657-62.

19. The International Study of Asthma and Allergies in Childhood (ISAAC) Steering Committee. Worldwide variations in the prevalence of asthma symptoms: the International Study of Asthma and Allergies in Childhood (ISAAC). Eur Respir J. 1998; 12(2):315-35.

20.Qureshi UA, Bilques S, ul Haq I, Khan MS, Qurieshi MA, Qureshi UA. Epidemiology of bronchial asthma in school children (10-16 years) in Srinagar. Lung India. 2016; 33(2): 167-73. doi: 10.4103/0970-2113. 177442
21. Liang PH, Shyur SD, Huang LH, Wen DC, Chiang $\mathrm{YC}$, Lin MT, et al. Risk factors and characteristics of early-onset asthma in Taiwanese children. J Microbiol Immunol Infect. 2006;39(5):414-21.

22. Ripabelli G, Tamburro M, Sammarco ML, de Laurentiis G, Bianco A. Asthma prevalence and risk factors among children and adolescents living around an industrial area: a cross-sectional study. BMC Public Health. 2013; 13(1):1038. doi:10.1186/1471-2458-131038

23. Xu XF, Li YJ, Sheng YJ, Liu JL, Tang LF, Chen ZM. Effect of low birth weight on childhood asthma: a meta-analysis. BMC pediatrics. 2014; 14(1): 275. doi: 10. 1186/1471-2431-14-275

24. Flaherman V, Rutherford GW. A meta-analysis of the effect of high weight on asthma. Arch Dis Child. 2006; 91(4):334-339.doi: 10.1136/adc.2005.080390

25. Jaakkola JJ, Ahmed P, Ieromnimon A, Goepfert $P$, Laiou E, Quansah R, Jaakkola MS. Preterm delivery and asthma: a systematic review and meta-analysis. $\mathrm{J}$ Allergy Clin Immunol. 2006; 118(4): 823-830. DOI: https:// doi.org/10.1016/j.jaci.2006.06.043

\section{How to cite this article?}

Dogra L, Bhatt S, Shetty D. Childhood bronchial asthma and its associated factors: a study from a tertiary care teaching hospital of coastal Karnataka, India. Int J Pediatr Res. 2019;6(07):366-371.doi:10. 17511/ijpr.2019.i07.09 